City University of New York (CUNY) CUNY Academic Works

2012

\title{
A Brief Introduction to Web-Based Note Capture
}

Steven Ovadia

CUNY La Guardia Community College

\section{How does access to this work benefit you? Let us know!}

More information about this work at: https://academicworks.cuny.edu/lg_pubs/10

Discover additional works at: https://academicworks.cuny.edu

This work is made publicly available by the City University of New York (CUNY).

Contact: AcademicWorks@cuny.edu 


\title{
INTERNET CONNECTIONS
}

\section{A Brief Introduction to Web-Based Note Capture}

\author{
STEVEN OVADIA \\ LaGuardia Community College, Long Island City, New York
}

We have used this space to discuss some of the ways to organize research, in terms of both bibliographic management and bookmarks (Ovadia, 2011, 2012). Perhaps just as important is the need to capture notes and ideas as one is conducting research. While physical notebooks and locally saved electronic files are certainly helpful, there are a number of web-based solutions that might be useful to someone conducting research online, or looking to hold their notes in a web-based environment. The main advantage of a web-based note capture tool is that one is able to access it from just about anywhere, as oppose to a locally saved file that is only available on one machine. This article explores web-based note-taking applications.

Evernote (www.evernote.com) might be one of the more popular examples of this kind of note-taking solution. In December 2011, Inc. magazine named Evernote its company of the year (Freedman 2011). Although it has appeal beyond academic audiences, many academics will probably be comfortable with the way Evernote works.

Evernote allows users to capture web pages, snippets of text, and images as users surf online. There is a stand-alone client that users can download, but also browser extensions for Firefox and Chrome that users can use to capture information. Where bookmarking tools, like delicious, capture URLs and perhaps a brief annotation provided by the bookmarker, Evernote allows users to capture URLs but also to copy parts of a web page. So if a user only wants to capture snippets of text or a certain image, the user can get that saved to Evernote using either the client, the browser extension, or e-mail. Users can also add text to whatever is saved, in case something needs context. Everything can be viewed and organized within the client or the web interface. Evernote will even save entire web pages, allowing users to have a static copy of a web page they may wish to refer to at a later point.

Address correspondence to Steven Ovadia, Library Media Resources Center, LaGuardia Community College, 31-10 Thomson Avenue, Long Island City, NY 11101. E-mail: sovadia@ lagcc.cuny.edu 
Basically, Evernote acts as a personal intranet, allowing users to capture pretty much whatever web-based content they want to capture. But beyond that, users can also annotate what they find. In fact, if one desired, one could simply use Evernote for notes, and not for capturing web content. For researchers who are using a lot of different types of web-based content, Evernote can be a nice tool for staying organized. However, it might not be a great fit for users who are relying on mostly academic material from subscription-based electronic collections. Evernote is more designed to capture anything and everything one encounters online. Tools like Mendley and Zotero are probably better options for organizing that kind of material, since they are optimized to work with academic documents. However, if so inclined, one could probably come up with a workflow for academic work; Evernote allows users to upload PDFs to their account, although there is a space limitation on free Evernote accounts.

Evernote has two service tiers: a free one, with space, note, and functionality limitations, and a paid one, without those limitations. Premium Evernote is $\$ 5 /$ month or $\$ 45$ year, as of this writing. The free level of service is probably more than sufficient for many users.

Evernote, in addition to having clients for Windows and Mac, also has iOS and Android versions, allowing users ubiquitous access to their notes across devices. But the ability to interact with Evernote via a web browser is very helpful, as it allows one access to one's notes, even if one is on a machine without Evernote installed.

Evernote is impressive in its seemingly infinite capabilities. But the learning curve can be a bit steep, since it is so comprehensive. Some alternative tools might be helpful for users looking for something a bit more familiar.

Diigo (www.diigo.com), discussed here in a previous column on bookmarking tools, is actually more than just a way to track bookmarks. While Diigo is a very effective bookmarking tool, it has additional functionality that could be helpful to someone actively engaged in web-based research, although, as with Evernote, if a user is primarily focused on academic sources, that user might be better off working with a citation management tool. However, if one is using a variety of web-based sources, Diigo is an interesting way to organize research.

In addition to capturing URLs, Diigo also allows users to annotate pages, either publicly or privately. These annotations can be seen as long as one is signed into one's Diigo account and is using a Diigo browser toolbar or via the Diigo web interface.

Diigo, like Evernote, also allows users to save web pages, or parts of web pages. But where Evernote has a robust note-taking area, Diigo users are limited to their web-page annotations, which display as virtual sticky notes on the page. Unlike Evernote, Diigo users cannot upload PDFs into to their accounts. 
Diigo does not have the robustness of Evernote, but its focus on enhanced bookmarking provides a simple workflow: Users find something online they wish to remember or find later and use Diigo to capture it and highlight or annotate it. For many researchers, this is more than sufficient.

Like Evernote, Diigo has an impressive free tier and a paid tier with access to more space and functionality. The pricing is comparable to Evernote's (as of this writing, there's a basic tier for $\$ 20 /$ year, a premium one for $\$ 5 /$ month or $\$ 40 /$ year, and a free plan for educators). But again, like Evernote, the free tier seems more than appropriate for most users who are just starting to use the service.

Another organization tool is Springpad (www.springpadit.com), which, like Diigo and Evernote, allows users to annotate and/or tag web links. Springpad, like Evernote, allows users to create stand-alone notes, although Springpad is rooted in the Post-It note visual metaphor. Like Evernote, Springpad users can also upload files, including PDFs, to their note area. Users can also add checklists to virtual notebooks, and, like the other tools discussed, there are also browser extensions to fold Springpad functionality into Firefox or Chrome, although the web interface works perfectly well. Springpad also has Android and iOS clients, which allow users to import information via a bar-code scan. Unlike Diigo and Evernote, Springpad does not allow users to save entire web pages, which, depending upon one's research, could be a significant issue. Springpad is free of charge. Springpad's recent redesign gives it a look and feel like Pinterest (www.pinterest.com), with an emphasis on visual sharing.

It is probably worth noting that while it is not a purely web-based tool, Microsoft OneNote does a lot of what Evernote and Springpad do, in terms of allowing users to capture content on the fly. OneNote is not a free product, but comes with Microsoft Office. Many academic institutions provide home versions of Office, so it is not something one might necessarily have to pay for out-of-pocket. OneNote is only available for Windows and does not have a web interface. However, OneNote notebooks can be shared across computers.

Diigo, Evernote, OneNote, and Springpad all have a web-capture component, which not everyone needs. Some people prefer to organize their research purely with text. There are quite a few web-based tools that allow users to organize text.

Some users use web-based word processors to organize themselves across multiple computers. For instance, something like Google Docs (docs.google.com) or Microsoft Office Live (www.officelive.com) can be used to create word-processed documents that are available from any web browser and most mobile devices.

For users looking for a simpler interface, a wiki might be even easier. A hosted wiki probably won't provide the same level of word-processing functionality as Google Docs or Office Live, but it is a quick and easy place 
to store files and notes. Wikis have a reputation for being collaborative, since they can be edited by anyone, but most hosted wikis, like PBworks (www.pbworks.com), allow users to maintain private wikis, or wikis that limit access. PBworks has a simple interface that lets users type in text, upload and link documents, and do some very light text formatting. For many users, something like PBworks is all that is needed to organize research. PBworks is free for personal, noncommercial use.

Another solution is Simplenote (www.simplenoteapp.com), a webbased tool for composing plain, unformatted notes. Think of it as an online text editor, like Windows Notepad. What makes Simplenote helpful is the variety of third-party clients that work with it. There are browser-based tools and tools for Android and iOS. This gives one access to notes, and the ability to add to them or reorganize them, from just about anywhere. Simplenote is free of charge, but has a premium tier for $\$ 1.99 /$ month or $\$ 19.99 /$ year that includes some additional functionality. Like the other tools discussed, the free tier is quite robust.

All of the tools discussed here have social elements allowing users to share whatever they've collected with other users. When deciding which capture tool to select, one should think about what it is one wants to capture. Some of these tools, like Diigo and Springpad, are more bookmark oriented, while others, like PBWorks and Simplenote, are more text oriented. And then there are tools like OneNote and Evernote, which seem to do everything.

The important thing is to find a tool that allows one to gather material and create notes in the most convenient way possible. For users on mobile devices, the mobile experience will obviously be more important than it is for users on desktop browsers or clients. The point is not to find the most full-featured tool so much as it is to find the tool that allows one to best capture and organize one's research. Users should also consider how easy it is to export data out of the application they have chosen. For instance, Springpad allows users to export their data as a single HTML file, which means comprehensive note sets might need to be reworked into different files, depending upon how one takes and organizes notes. Evernote, as another example, allows users to export individual notebooks (or all of them), in either one HTML file or individual, notebook-based ones. Each application has its own export/backup formatting, and it's important to make sure one is not entering important data into something it might later prove difficult to export data out of.

Finally, this article does not discuss the use of these tools in a pedagogical context, but instead focuses on how active researchers might use these applications to organize their own research. It is worth noting that there is much in the literature to support the pedagogical use of many of the tools discussed here. Estellés, del Moral, and González looked at social bookmarking tools and their role in learning, specifically examining Diigo (2010). They found that "Diigo is extremely useful to develop digital 
competencies directly related to information search, management, analysis and categorization" (189). Schepman, Rodway, Beattie, and Lambert studied how undergraduate students used Evernote, finding that most of their subjects liked and recommended the tool $(2012,316)$. Ras and Rech studied the use of wikis in graduate/undergraduate capstone projects and found that they helped in knowledge acquisition $(2009,561)$. Luo found many librarians using social bookmarking tools and wikis in information instruction (2010, 38). Redden studied the use of social bookmarking in academic libraries and found they had information literacy applications (2010, 226). For those interested in more research, Novak, Razzouk, and Johnson recently published a literature review studying social annotation tools in higher education (2012).

\section{REFERENCES}

Estellés, E., E. del Moral, and F. González. 2010. Social bookmarking tools as facilitators of learning and research collaborative processes: The Diigo case. Interdisciplinary Journal of E-Learning and Learning Objects 6:175-91.

Freedman, D. H. 2011. Say hello to your new brain. Inc 33(10): 70-78.

Luo, L. 2010. Web 2.0 integration in information literacy instruction: An overview. Journal of Academic Librarianship 36(1): 32-40.

Novak, E., R. Razzouk, and T. E. Johnson. (2012). The educational use of social annotation tools in higher education: A literature review. The Internet and Higher Education 15(1): 39-49.

Ovadia, S. 2011. Managing citations with cost-free tools. Behavioral E Social Sciences Librarian 30(2): 107-11.

Ovadia, S. 2012. Syncing bookmarks: An overview of current options. Behavioral $\varepsilon$ Social Sciences Librarian forthcoming.

Ras, E., and J. Rech. 2009. Using wikis to support the net generation in improving knowledge acquisition in capstone projects. Journal of Systems and Software 82(4): 553-62.

Redden, C. S. 2010. Social bookmarking in academic libraries: Trends and applications. Journal of Academic Librarianship 36(3): 219-27.

Schepman, A., P. Rodway, C. Beattie, and J. Lambert. 2012. An observational study of undergraduate students' adoption of (mobile) note-taking software. Computers in Human Behavior 28(2): 308-17. 